\title{
Tradições do êxodo em Sb 11-19
}

\author{
Exodus Traditions in Wisdom 11-19
}

Cássio Murilo Dias da Silva

\section{Resumo}

Este artigo tem duplo objetivo. Em primeiro lugar, expor de modo sistemático a releitura que Sb 11-19 faz dos episódios exodais, desde as pragas que preparam a saída dos hebreus do Egito, até os acontecimentos do tempo do deserto. Trata-se de um grande midrash, no qual cada castigo imposto aos egípcios (símbolo dos ímpios) equivale a um evento salvífico para Israel (símbolo dos justos). Segundo, fazer uma releitura da releitura e apresentar textos do NT que herdaram a intepretação que o grande midrash faz dos eventos exodais, uma vez que apresentam os mesmos conceitos, o mesmo vocabulário ou a mesma formulação do encontrado nas sete antíteses do grande midrash.

Palavras-chave: Exxodo; Sabedoria; midrash; pragas do Egito.

\section{Abstract}

This paper has a double purpose. First, expose systematically the reading that $\mathrm{Sb}$ 11-19 does of exodus episodes, since the plagues that prepare the departure of the Hebrews from Egypt until the events in desert. It is a great midrash, in which each punishment imposed on Egyptians (symbol of the wicked) equates to a saving event for Israel (symbol of the righteous). Second, to re-read the re-reading and expose the texts in the NT which inherited the interpretation that great midrash does of the exodus events, as they present the same concepts, the same vocabulary and the same formulation found in the seven antitheses of the great midrash. 
Keywords: Exodus; Wisdom; midrash; plagues of Egypt.

\section{Introdução}

Os dez últimos capítulos do livro da Sabedoria reelaboram diversas tradições do êxodo-evento e do Êxodo-livro, bem como do livro de Números, e podem ter servido de ponte para os autores do Novo Testamento compreenderem a revelação neotestamentária.

Por ser um dos livros da Bíblia Grega $(\mathrm{LXX})^{1}$, mas não da Bíblia Hebraica ( TaNaK), Sabedoria é um livro que integra a Bíblia católica, mas não as escrituras da Sinagoga, nem a Bíblia dos protestantes, evangélicos e pentecostais. Mesmo entre os católicos, é pouco estudado e lido apenas fragmentariamente.

Por isso, convém iniciar este artigo com dois pontos preliminares ${ }^{2}$ : uma rápida introdução ao livro da Sabedoria ${ }^{3}$, para situar o leitor não familiarizado com o livro e sua teologia; depois, uma visão panorâmica dos capítulos 10-19.

\section{O livro da Sabedoria}

\subsection{Autor, data e local}

Com o título "Sabedoria de Salomão" (Sophía Salōmōnos), a Septuaginta identifica um livro de dezenove capítulos que, sem nenhuma dúvida,

\footnotetext{
${ }^{1}$ Para o texto da LXX (história, formação, função e motivos), ver: Peters, Melvin K.H. Septuagint. In: Freedman, David Noel (ed). The Anchor Bible Dictionary. New York: Doubleday, 1992, vol. 5, pp. 1097-1100; Tilly, Michael. Introdução à Septuaginta. São Paulo: Loyola, 2009, pp. 31-65; MunNich, Olivier. O texto da Septuaginta e seus problemas. In: HarL, Marguerite; Dorival, Gilles \& Munnich, Olivier. A Bíblia grega dos Setenta. São Paulo: Loyola, 2007, pp. 119-181; Gilbert, Maurice. Sagesse de Salomon. In: Pirot, Louis e outros. Supplément au Dictionnaire de la Bible. Paris: Letouzey et Ané, 1986, vol. 11, cols. 58-65.

${ }^{2}$ Este artigo é uma versão ampliada de minha conferência "As tradições do Êxodo no livro da Sabedoria", proferida no II Colóquio de Exegese do Antigo Testamento, organizado pelo Grupo de Pesquisa DIPRAI (“As Dimensões Proféticas da Religião do Antigo Israel”) e realizado pelo Setor de Língua e Literatura Hebraicas do Departamento de Letras Orientais e Eslavas da Faculdade na Letras da UFRJ, no período de 13 a 15 de outubro de 2014.

${ }^{3}$ Introduções mais detalhadas encontram-se em: Winston, David. Solomon, Wisdom of. In: Freedman, David Noel (ed). The Anchor Bible Dictionary. New York: Doubleday, 1992, vol. 6, pp. 120-127; Ravasi, Gianfranco. Sapienza (Libro della). In: Rossano, Pietro; Ravasi, Gianfranco \& Girlanda, Antonio, eds. Nuovo Dizionario di Teologia Biblica. Cinisello Balsamo: Paoline, 1988, pp. 1142-1447; Vílchez Líndez, José. Sabedoria. São Paulo: Paulus, 1995, pp. 11-100. Para uma introdução breve e didática, ver Silva, Cássio Murilo Dias da \& Ló, Rita de Cácia. Caminho não muito suave. Campinas, Alínea, 2011, pp. 93-104.
} 
não foi escrito pelo Salomão, filho de Davi e rei de Jerusalém, entre os anos 970 e 931 a.C.

As razões para considerar a atribuição a Salomão como um típico caso de pseudonímia são várias":

- o autor conhecia a filosofia platônica (cerca de 500 anos após Salomão) e outras correntes do pensamento grego clássico;

- o livro está ambientado no mundo helenista, mais precisamente, Alexandria no Egito, realidades históricas muito posteriores a Salomão;

- a língua do livro é o grego helenista (não o grego dos autores clássicos nem dos filósofos, mas o grego usado como língua franca nos territórios conquistados por Alexandre), ou seja, um idioma também surgido séculos após Salomão;

- no final do livro da Sabedoria, encontra-se um encorajamento aos judeus que sofrem perseguições, uma situação inexistente no tempo de Salomão.

Estes e outros indícios levam a afirmar que o livro da Sabedoria foi escrito em Alexandria, no Egito, entre os anos 30 e 14 a.C. De fato, neste período, Alexandria contava com uma florescente comunidade judaica, que cultivava as letras e as artes, mas também lutava para conservar a própria cultura e para se manter no mesmo padrão cultural da grande cidade em que se encontrava ${ }^{5}$.

Embora Alexandria fosse uma cidade fundada por Alexandre (e, portanto, inexistente no período equivalente ao que o êxodo se encaixa), a cultura do Antigo Egito impregnava a vida e a cultura da cidade. Não é à toa, portanto, que os capítulos 13-15 do livro da Sabedoria façam uma crítica feroz contra a zoolatria (adoração de animais), algo muito comum no Egito.

\footnotetext{
${ }^{4}$ Para a pessoa de Salomão, a discussão tomou novos rumos nas últimas décadas. Instigadora é abordagem de Lemche, Niels Peter. Jerusalem and King Solomon: How Writers Create the Past. In: Liverani, Mario e outros. Convegno Internazionale "Recenti tendenze nella ricostruzione della storia antica d'Israele”. Roma, Academia Nazionale dei Lincei, 2005, pp. 73-86. Ver também Ishida, Tomoo. Solomon. In: Freedman, David Noel (ed). The Anchor Bible Dictionary. New York, Doubleday, 1992, vol. 6, pp. 105-113; Hamilton, Mark W. Solomon. In: SAKENFIELD, Katharine Doob (ed). The New Interpreter's Dictionary of the Bible. Nashville, Abingdon, 2009, vol. 5, pp. 317-326.

${ }^{5}$ Para informações mais extensas sobre Alexandria e sua comunidade judaica, ver PEARson, Birger A. Alexandria. In: Freedman, David Noel (ed). The Anchor Bible Dictionary. New York, Doubleday, 1992, vol. 1, pp. 152-157; BAsLEz, Marie-Françoise. L'Autore della Sapienza e l'ambiente colti de Alessandria. In: Bellia, Giuseppe \& PASSARo, Angelo (eds). Il Libro della Sapienza: tradizione, redazione, teologia. Roma: Città Nuova, 2004, pp. 47-66.
} 


\subsection{Organização e mensagem}

O público-alvo do autor é duplo: os judeus e os pagãos.

Aos judeus, que passam por um período de perseguição e menosprezo, a mensagem é de encorajamento: eles devem se manter firmes na fé e na fidelidade, ainda que o tempo presente seja de tribulação.

Aos pagãos, isto é, aos não judeus, a mensagem é de instrução: a sabedoria de Israel é superior à filosofia grega.

Esta dupla finalidade o livre faz de Sabedoria um escrito "sapiencialapocalíptico". Sapiencial, porque visa instruir os pagãos; apocalíptico, porque quer sustentar os judeus na fét.

Estes dois aspectos, no entanto, não se encontram rigidamente demarcados no livro. Ao contrário, estão amalgamados de modo insolúvel. Assim, o mesmo ensinamento é sempre apresentado com as duas facetas.

O conjunto do livro é composto por três partes, correspondentes a três aspectos da Sabedoria ${ }^{7}$ :

1,1-6,21: A Sabedoria como norma de vida

6,22-9,18: A Sabedoria em si mesma

10,1-19,22: A Sabedoria na história da salvação

\subsection{A Sabedoria como norma de vida}

Há uma clara formulação da doutrina da imortalidade $(2,23 ; 3,4 \mathrm{~b}$; 8,13 a e outros). Sem dúvida, a filosofia de Platão ofereceu categorias para se pensar na vida após a morte, mas a imortalidade pregada em Sabedoria não é a consequência metafísica da imortalidade da alma, e sim a imortalidade

\footnotetext{
${ }^{6}$ Seguindo a proposta de Conti, Martino. Sapienza. In: Girlanda, Antonio, ed. La Bibbia: Nuovissima versione dei testi originali. Cinisello Balsamo: Paoline, 1991, vol. 3, p. 810. Para a discussão acerca do gênero literário do livro da Sabedoria, ver VílchEz Líndez, José. Sabedoria. São Paulo: Paulus, 1995, pp. 23-39. Mais brevemente: Doré, Daniel. El libro de la Sabiduría de Salomón. Estella: Verbo Divino, 2003, pp.11-13; Ravasi, Gianfranco. Sapienza (Libro della). In: Rossano, Pietro; Ravasi, Gianfranco \& Girlanda, Antonio, eds. Nuovo Dizionario di Teologia Biblica. Cinisello Balsamo: Paoline, 1988, pp.1442-1443.

${ }^{7}$ Sobre a estrutura do livro e a organização da mensagem de Sabedoria, ver GILBERT, Maurice. Sagesse de Salomon. In: Pirot, Louis e outros. Supplément au Dictionnaire de la Bible. Paris: Letouzey et Ané, 1986, vol. 11, cols. 72-77; Vílchez LínDEZ, José. Sabedoria. São Paulo: Paulus, 1995, pp. 13-17; Doré, Daniel. El libro de la Sabiduría de Salomón. Estella: Verbo Divino, 2003, pp. 10-11; KolarciK, Michael. Solomon, Wisdom of. In: Sakenfield, Katharine Doob (ed). The New Interpreter's Dictionary of the Bible. Nashville, Abingdon, 2009, vol. 5, pp. 331-332.
} 
beatífica, isto é, o dom que Deus reserva aos que viverem em comunhão com ele, praticando a justiça $(1,15 ; 4,1 b ; 87,13 a)$.

\subsection{A Sabedoria em si mesma}

A Sabedoria divina (com "s" maiúsculo) e a sabedoria humana (com "s" minúsculo) não se contradizem nem são antagônicas. Ao contrário, a sabedoria humana é a participação na Sabedoria divina. Deste modo, na segunda parte do livro, o conceito "sabedoria" é usado para definir o relacionamento homem-Deus. Em outras palavras, a Sabedoria/sabedoria é a mediação entre Deus e o homem, o mundo e a história. Isso está muito bem explicitado em $7,22-24$, texto que servirá de base para a escola joanina formular a doutrina sobre o Verbo encarnado (Jo 1; 1Jo 1,5).

\subsection{A Sabedoria na história da salvação}

A presença e a ação da Sabedoria na história são apresentadas em uma releitura dos eventos narrados em Gênesis, Êxodo e Números, bem como a pregação do Deuteronômio e algumas tradições targúmicas acerca de Ex 15,2. O capítulo 10 relê as narrativas bíblicas de Adão a Moisés; os capítulos 11-19 releem os acontecimentos do êxodo e da travessia do deserto. Trata-se de um grande midras $^{8}$, isto é, um comentário tipicamente rabínico, no qual textos da Escritura são interpretados livremente e atualizados para as novas circunstâncias vividas pela comunidade, com aplicações teológicas e morais.

Além do gênero midráshico, pertencente à cultura judaica, o autor utiliza também outro procedimento literário, emprestado da cultura helenista: a síncrise ou comparação de opostos ${ }^{9}$. Por meio deste recurso, o autor elabora

\footnotetext{
${ }^{8}$ Há dois tipos de midrash: o midrash halákico e o midrash hagádico. O primeiro, midrash halákico, relê e atualiza textos legislativos; o segundo, midrash hagádico, relê e atualiza textos narrativos. Para os tipos de midrash e outros comentários da literatura rabínica, ver KETTERER, Eliane \& Remaud, Michel. O midraxe. São Paulo, Paulus, 2009, pp. 16-17; TARAdACH, Madeleine. El midrash. Introdució a la literatura midràshica, als targumim i als midrashim. Barcelona, Herder, 1989, pp. 21-25; Visotzky, Burton L. Midrash. In: SAKEnfield, Katharine Doob (ed). The New Interpreter's Dictionary of the Bible. Nashville, Abingdon, 2009, vol. 4, pp. 81-84.

9 Para a figura de discurso "sincresis", ver Bullinger, Ethelbert W. Figures of Speech used in the Bible: Explained and Illustrated. London - New York, Eyre \& Spottiswoode - E. \& J.B. Young, 1898, p. 734.
} 
sete antíteses, nas quais os mesmos acontecimentos ou acontecimentos equivalentes são salvação para o povo de Israel (o símbolo do povo de justos) e perdição para o Egito (o modelo do povo de ímpios empedernidos).

São três os personagens principais, assim identificados:

- a Sabedoria de Deus, aquela que protegeu e salvou o povo do Senhor;

- o povo do Senhor, Israel, o povo santo, a nação irrepreensível, o(s) justo(s), o(s) santo(s): não se trata do Israel histórico, e sim do Israel que simboliza os justos e fiéis a Deus.

- os inimigos, o Egito, a nação dos opressores, os injustos: igualmente, não o Egito histórico, e sim o Egito como símbolo dos inimigos, dos ímpios.

\section{A Sabedoria na história da salvação: visão panorâmica}

No capítulo 10, na sua galeria de personagens tirados do livro do Gênesis - de Adão a Noé (vv. 1-4), Abraão (v. 5), Ló (vv. 6-9), Jacó (vv. 10-12) e José (vv. 13-14) - o autor se apropria livremente dos relatos bíblicos e os coloca sob a luz da ação salvífica da Sabedoria. Mas é um relato apressado, que conduz rapidamente a Moisés (vv. 15-21) e, com ele, aos acontecimentos que de fato importam, isto é, os eventos do êxodo.

Os capítulos 11-19 descrevem a manifestação do juízo histórico de Deus na história. Os vários aspectos são apresentados por meio de sete antíteses que transformam os acontecimentos ocorridos durante a saída do Egito em eventos meta-históricos e, portanto, escatológicos, que descrevem a derrota dos ímpios (o Egito) e a salvação dos justos (o povo eleito, Israel).

O grande midrash propriamente dito ocupa 11,2-14 e 16,1-19,9, pois é interrompido por duas digressões $(11,15-12,27$ e 13,1-15,19). Os últimos versículos $(19,10-22)$ são reflexões conclusivas.

Esquematicamente:

10,1-21: Da criação ao êxodo

11,1-14: O grande midrash sobre o êxodo - uma antítese

11,15-12,27: $1^{\text {a }}$ digressão: a moderação divina

13,1-15,19: $2^{\text {a }}$ digressão: a idolatria

16,1-19,9: O grande midrash sobre o êxodo - seis antíteses

19,10-22: Reflexões finais (com breve oração conclusiva) 


\subsection{As duas digressões}

Uma vez que o interesse desta exposição recai sobre as sete antíteses, trataremos apenas sumariamente das duas digressões ${ }^{10}$.

A primeira delas, sobre a moderação divina, é composta de três grandes partes:

\section{1,15-12,2: moderação para com o Egito}

12,3-18: moderação para com Canaã

12,19-27: conclusão

A segunda, sobre a idolatria, é um setenário, organizado de modo quiástico:

13,1-9: divinização das forças da natureza e dos astros (1)

13,10-15,13: culto aos ídolos

A - 13,11-19: o carpinteiro idólatra (2)

B - 14,1-10: o marinheiro idólatra (3)

C - 14,11-14: invenção, consequências e castigo da idolatria

D - 14,15-21: divinização dos mortos e dos reis (4 e 5)

C'-14,22-31: consequências: imoralidade, fetichismo, mistérios

B' - 15,1-6: invocação, transição

A' - 15,7-13: o oleiro idólatra (6)

15,14-19: zoolatria dos egípcios (7)

\section{O grande midrash sobre o êxodo}

Novamente, estamos diante de um setenário de antíteses de acontecimentos que são perdição para o Egito (= o povo dos ímpios) e salvação para Israel (= o povo dos justos).

\subsection{Sumário introdutório e tema geral da homilia}

Um sumário introdutório (11,1-4) remete a Ex 12,37-17,7 e Nm 20,213: o "santo profeta" é Moisés, que conduz os israelitas através do deserto até a Terra Prometida. O v. 3 remete ainda aos episódios nos quais os israelitas

${ }^{10}$ Exposições mais detalhadas encontram-se em Vílchez Líndez, José. Sabedoria. São Paulo: Paulus, 1995, pp. 258-337 (com exegese de cada versículo); GilbERT, Maurice. Sagesse de Salomon. In: PIROT, Louis e outros. Supplément au Dictionnaire de la Bible. Paris: Letouzey et Ané, 1986, vol. 11, cols. 110-112; Doré, Daniel. El libro de la Sabiduría de Salomón. Estella: Verbo Divino, 2003, pp. 42-58; e o minucioso LARCHER, Claudine. Le Livre de la Sagesse ou la Sagesse de Salomon. Paris: Gabalda, 1985, vol. 3, pp. 671-887. 
enfrentam povos e reis inimigos: os amalecitas (Ex 17,8-15); o rei cananeu de Arad (Nm 21,1-3); Seon, o rei amorreu de Hesebon (Nm 21,21-24; Dt 2,31-33); Og, o rei amorreu de Basã (Nm 21,33-35; Dt 3,1-7); os moabitas (Nm 22,1-6); os madianitas (Nm 25,16-18; 31,1-12).

A seguir, o autor apresenta o princípio geral (v. 5) que norteará toda terceira parte do livro e, mais especificamente, as sete antíteses. Literalmente:

"De fato, aquilo por meio do qual seus inimigos eram punidos, Por meio dessas mesmas coisas, eles, no apuro, eram beneficiados”.

Este princípio é repetido com diversas formulações ao longo do midrash $(11,13 ; 16,2.24 ; 18,8)$ e será ilustrado nas sete antíteses. Graficamente:

\begin{tabular}{llclc} 
& & para Israel / os justos & $\mathrm{x}$ & para o Egito / os impios \\
\hline 1) & $11,6-14:$ & água pura da rocha & $\mathrm{x}$ & águas ensanguentadas do Nilo \\
\hline 2) & $16,1-4:$ & codornizes & $\mathrm{x}$ & rãs \\
\hline 3) & $16,5-14:$ & serpente de bronze & $\mathrm{x}$ & gafanhotos e moscas \\
\hline 4) & $16,15-29:$ & maná & $\mathrm{x}$ & granizo e fogo \\
\hline 5) & $17,1-18,4:$ & luz & $\mathrm{x}$ & trevas \\
\hline 6$)$ & $18,5-25:$ & anjo libertador & $\mathrm{x}$ & anjo exterminador \\
\hline 7) & $19,1-9:$ & o mar se abre & $\mathrm{x}$ & o mar se fecha \\
\hline
\end{tabular}

3.2. Primeira antítese: a água da rocha e as águas do Nilo

Esta antítese tem como tema a água, como instrumento de castigo (para o Egito) e de bênção (para Israel). Os textos inspiradores são:

- Ex 7,17-25: a primeira praga, na qual a água do Nilo é transformada em sangue;

- Ex 17,1-7 e Nm 20,2-13: dois textos sobre murmurações por falta de água e milagres idênticos (Moisés fere uma rocha e dela jorra água em abundância).

Em ambos os casos, a sede está envolvida: como consequência da primeira praga; como motivadora da murmuração contra Moisés e contra 
Yнwн. Para os egípcios, a sede é um castigo insuperável; para os hebreus, é uma prova corretiva que levará à manifestação da misericórdia divina (temática tomada de Dt 8,2-5).

3.3. Segunda antítese: as codornizes e as rãs

O segundo confronto baseia-se na aparição de pequenos animais: rãs para torturar egípcios, codornas para salvar hebreus. Os textos inspiradores são:

- Ex 7,27-8,10: a segunda praga, na qual rãs invadem o Egito;

- Ex 16,13 e Nm 11,31-32: por duas vezes, codornizes invadem o acampamento hebreu.

No relato da segunda praga, jamais se alude a um possível consumo da carne das rãs invasoras, nem mesmo para qualificar o Egito como um país com costumes impuros.

Enquanto o livro do Exxodo se fixa no incômodo provocado pelo excesso de rãs entre os egípcios, o midrash do livro da Sabedoria fala da náusea provocada pelas rãs, como uma tortura que faz os egípcios perderem até mesmo o apetite. Opostamente, as codornizes vêm saciar a fome e o apetite dos hebreus.

Há de se acrescentar a observação de Sb 19,10-12: tanto as rãs como as codornizes tem origem aquática, uma vez que o rio "vomitou rãs", enquanto "as codornizes subiram do mar".

3.4. Terceira antítese: a serpente de bronze e os gafanhotos e as moscas

Animais que picam são os actantes ${ }^{11}$ do terceiro confronto, que amálgama três pragas. Os textos inspiradores são:

- Ex 8,12-15: a invasão de mosquitos (terceira praga);

- Ex 8,16-20: a invasão de moscas (quarta praga);

- Ex 10,12-20: a invasão de gafanhotos (oitava praga);

- Nm 21,4-9: a invasão de serpentes.

Não deixa de provocar perplexidade a combinação. Quando se pensa no dado objetivo, logo se recorda que mosquitos, moscas e gafanhotos não

\footnotetext{
${ }^{11}$ Para a definição de "actante" e outros termos usados na leitura semiológica/semiótica de textos, ver Greimas, Algirdas Julien \& Courtés, Joseph. Dicionário de semiótica. São Paulo: Cultrix, 1989; Babolin, Sante. Piccolo lessico di semiotica. Roma, Hortus Conclusus, 1999.
} 
são animais venenosos, mas que serpentes o são. No entanto, na antítese, os animais portadores do castigo e extermínio são exatamente os inofensivos insetos, enquanto as peçonhentas víboras são associadas à salvação (as mordidas destes animais dão ocasião para a ação misericordiosa de Deus). Tal inversão pode acontecer porque o midrash toma como ponto de referência não os fatos, mas a interpretação teológica dos episódios.

3.5. Quarta antítese: o maná e o granizo e o fogo

Os elementos envolvidos na quarta antítese têm em comum sua origem celeste. Os textos inspiradores são:

- Ex 9,13-35: a sétima praga, na qual granizo e fogo caem do céu para afligir os egípcios;

- Ex 16: o maná cai do céu para sustentar os hebreus.

No relato da sétima praga, o termo "fogo" não indica somente o relâmpago (isto é, o aspecto visível dos trovões), mas também o efeito dos raios quando atingem a terra. Além disso, os vários elementos cósmicos utilizados na narrativa - fogo, granizo, trovão, chuva - transformam gradualmente a descrição da praga em uma típica teofania do $\mathrm{AT}^{12}$. Ao granizo, o midrash associa neve e gelo, inexistentes no relato do livro do Êxodo. Tal acréscimo é natural, uma vez que granizo, neve e gelo são três configurações do mesmo elemento: a água em estado sólido. Trata-se de uma acumulação de imagens para acentuar a contraposição com o outro elemento cósmico igualmente transformado em arma de castigo contra o Egito: o fogo. O midrash afirma explicitamente que o fogo não derretia gelo e neve, de modo a fundir os dois extremos e assim tornar ainda mais pesado a punição. Um oximoro ${ }^{13}$ de forças da natureza, com um poder de destruição do qual é impossível escapar.

Para os hebreus, porém, cai do céu o "manjar dos anjos" e o "pão do céu", capaz de satisfazer todo desejo.

Outros textos subjacentes à antítese: Nm 11,6-9; 21,5 e Dt 8,3-16, nos quais o maná é um alimento humilhante e do qual o povo está enjoado. Acrescente-se ainda Js 5,12, que contrapõe o maná aos produtos da terra.

${ }_{12}$ Sobre isso, ver Silva, Cássio Murilo Dias da. Aquele que manda a chuva sobre a face da terra. São Paulo: Loyola, 2006. pp. 49-53.

${ }^{13}$ Para esta figura de linguagem, ver Bullinger, Ethelbert W. Figures of Speech used in the Bible: Explained and Illustrated. London - New York, Eyre \& Spottiswoode - E. \& J.B. Young, 1898. pp. 816-818. 
Na quinta antítese é a mais longa. Nela, o autor demonstra grande fantasia criativa, uma vez que supre dados faltantes nos relatos do livro do Êxodo. Os textos inspiradores são:

- Ex 10,21-23: as trevas densas e palpáveis (nona praga);

- Ex 13,21-22 e 40,38: a coluna de fogo, que ilumina o acampamento hebreu durante a noite;

- Ex 14,19-20.24; Nm 10,34; 14,14 e Dt 1,33: a coluna de nuvem durante o dia; a coluna de fogo durante a noite.

Também as trevas são instrumentos da punição divina. $O$ autor do midrash descreve detalhadamente os vários aspectos deste castigo, concentrando-se quase exclusivamente nos efeitos psicológicos do pavor provocado pelas trevas. $\mathrm{O}$ interessante desta descrição é que o medo e a angústia são os sentimentos opostos ao poder e à prepotência: os arrogantes egípcios entram em pânico e se tornam covardes e psicóticos. Os hebreus, ao contrário, caminham na luz e na serenidade.

Novamente, o autor joga com o sentido material e o sentido figurado de luz e trevas.

3.7. Sexta antítese: o anjo libertador e o anjo exterminador

A morte dos primogênitos egípcios e a páscoa dos hebreus constituem a sexta antítese. Os textos inspiradores são:

- Ex 1,15-22: o infanticídio promovido pelo Faraó;

- Ex 11-12: a morte dos primogênitos egípcios (a décima praga, como vingança de YHwH ao infanticídio do capítulo 1) e a celebração da páscoa dos hebreus.

O relato de Ex 11-12 não é linear, pois funde e alterna tradições acerca da morte dos primogênitos, da festa da páscoa com o cordeiro e da festa dos pães ázimos.

O midrash novamente toma como ponto focal o significado dos fatos narrados no livro do Êxodo, mas se concentra na morte dos filhos dos egípcios, apenas alude ao sacrifício do cordeiro, e omite totalmente os ázimos. De modo 
bastante natural, passa das trevas da quinta antítese para a noite da páscoa. $\mathrm{Na}$ mesma toada da antítese anterior, há uma preocupação em descrever a reação e os efeitos psicológicos dos egípcios ante a morte de seus filhos. $\mathrm{O}$ autor tem ainda o cuidado de incluir todas as classes e categorias sociais entre os vitimados pelo extermínio, de modo a sublinhar o poder e a radicalidade da intervenção divina.

Além disso, no midrash, quem efetivamente executa o massacre é a onipotente Palavra de Deus, que desce do céu brandindo a espada afiada da ordem divina!

Aos hebreus, porém, está reservada a sobrevivência: no deserto, lugar em que os alcançou uma provação mortal, novo mensageiro divino lhes garantiu a vida, igualmente manejando "armas" para defendê-los.

3.8. Sétima antítese: o mar que se abre e o mar que se fecha

As antíteses acerca da libertação de Israel são completadas com o episódio do Mar dos Juncos. Os textos inspiradores são:

- Ex 14,15-31: a passagem do "Mar Vermelho";

- Nm 33,2-4: recordação do dia após o extermínio dos inocentes;

Esta é a única antítese que não se refere a uma das pragas que assolaram o Egito. Não obstante, é a mais trágica de todas. Novamente, um elemento cósmico é instrumento de castigo para egípcios e de libertação para hebreus. O que há de particular agora é que, como clímax da punição, a água se transforma no lugar da sepultura dos perversos.

Novamente, a água é elemento salvífico para os hebreus, destruidor para os egípcios, retomando assim a primeira antítese.

Inspirando-se também em Is 63,11-14 e S1 114, o midrash celebra a passagem do Mar Vermelho com uma ação de graças ao Senhor libertador.

Não obstante esta celebração do Deus libertador, esta última antítese celebra igualmente o Deus criador, uma vez que retoma o esquema da criação de Gn 1,1-2,4a. Os vários elementos de contato são: caos, trevas, sopro de Deus; a terra que emerge da água; a erva verdejante da terra. Esses contatos se prolongam também nos restantes versículos de Sb 19: animais do céu e da terra; luz e trevas; alimento da terra. 


\section{O grande midrash sobre o êxodo e o Novo Testamento}

Agora, a releitura da releitura, que visa demonstrar como o Novo Testamento utilizou o grande midrash sobre o Exxodo, o que em outras palavras significa estudar como Sb 11-19 serviu de ponte para a compreensão da revelação neotestamentária.

Seguindo a opção do ponto precedente, esta abordagem concentra sua atenção nas sete antíteses de Sb 11,6-9 e 16,1-19,9. Nos textos do NT que direta ou indiretamente se vinculam às sete antíteses, está ausente somente a segunda: codornizes $\mathrm{X}$ rãs ${ }^{14}$. Serão expostos somente os textos mais significativos e seguros. A exposição seguirá a ordem dos versículos em Sabedoria ${ }^{15}$.

\subsection{Primeira antítese: a água da rocha e as águas do Nilo}

A afirmação paulina "não vos escrevo isto para vos envergonhar, e sim para vos corrigir como filhos amados" (1Cor 4,14) retoma o afirmado em Sb 11,10: "de fato, Tu os provaste como um pai que adverte", ideia tomada de Dt 8,5.

\subsection{Terceira antítese: a serpente de bronze e os gafanhotos e as moscas}

A versão paulina da última ceia é a única a trazer frase "fazei isto em memória de mim" (1Cor 11,24; literalmente: "para a minha memória") e retoma o conceito "anámnēsin"16, presente em Sb 16,6: "em/para memória do mandamento da tua Lei". O versículo de Sabedoria fala da serpente de bronze (Nm 21,8-9) como sinal de salvação; semelhantemente, a ceia do Senhor é apresentada também como sinal de salvação, mas que pode se tornar também condenação (1Cor 11,17-34).

\footnotetext{
${ }^{14}$ Embora Ap 16,13 empregue bátrachoi - rãs, este termo é usado em Sb 19,10, já nas reflexões finais do midrash, mas não na segunda antítese (Sb 16,1-4: codornizes X rãs). Se o texto de Apocalipse se referir à praga das rãs, em Ex 7,25-8,11, trata-se de um vínculo direto com 0 relato do livro do Êxodo, sem usar a antítese de Sabedoria como ponte. Portanto, não se encaixa na abordagem proposta na quarta parte deste artigo.

${ }^{15}$ Um elenco abrangente dos textos de Sb 10-19 citados direta ou indiretamente pelo NT, com o seu correspondente neotestamentário, encontra-se ao final das várias edições de NestLE, Eberhard \& Aland, Kurt (eds). Novum Testamentum Graece. Stuttgart, Deutsche Bibelgesellschaft: $26^{\mathrm{a}}$ edição, 1979, p. 773; $27^{\mathrm{a}}$ edição, 1993, p. 804; $28^{\mathrm{a}}$ edição, 2012, p. 874.

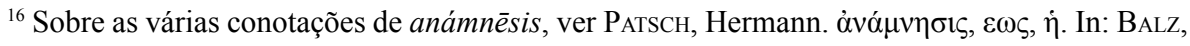
Horst \& SchneIDER, Gerhard, eds. Diccionario Exegetico del Nuevo Testamento. Salamanca: Sigueme, 1996, vol. 1, cols. 251-254.
} 
Em Ap 9,3, o poder mortal dado aos gafanhotos, "semelhante ao poder dos escorpiões" repete Sb 11,9: "mataram-nos as picadas de gafanhotos e de moscas".

Em 1Cor 7,35, Paulo afirma que suas recomendações para pessoas não-casadas, virgens e viúvas não têm a finalidade de "preparar uma armadilha", e sim orientar "ao que é digno e conduz ao Senhor sem distrações". É possível coligar tal afirmação a Sb 16,11.

Os efeitos terapêuticos da Palavra do Senhor, afirmados em Sb 16,12, são retomados em Jo 6,63: "As palavras que vos falei são espírito e vida".

$\mathrm{O}$ poder/autoridade atribuído a Cristo e aplicado à sua ressurreição, em $\mathrm{Rm}$ 10,7, “Quem descerá até o abismo?, isto significa Cristo subir dos mortos", é transposição cristológica da prerrogativa divina descrita em $\mathrm{Sb}$ 16,13: "Com efeito, tu tens o poder/autoridade sobre a vida e sobre a morte, conduzes às portas do Hades ${ }^{17}$ e trazes de volta", e em Dt 30,12-14: "Quem subirá até o céu...? Quem atravessará o mar...?”.

4.3. Quarta antítese: o maná e o granizo e o fogo

A catástrofe deflagrada pela primeira trombeta, em Ap 8,7, é assim descrita: "houve granizo e fogo, misturados com sangue, e foram lançados sobre a terra". Trata-se de uma nova versão do oximoro das forças cósmicas amalgamadas em Sb 16,26: "neve e gelo suportavam o gelo e não derretiam, para que soubessem que ofogo que ardia no granizo e relampeava nas chuvas destruía os frutos dos inimigos".

Como resposta à primeira tentação no deserto, em Mt 4,4 Jesus responde: "não só de pão viverá o homem, mas de toda palavra que sai da boca de Deus". O texto citado é Dt 8,3, mas não conforme a Bíblia Hebraica, e sim conforme a Septuaginta, que Sb 16,26 relê e aplica ao destino do justo: "não é a diversidade de frutos que alimenta o homem, mas é a tua palavra que faz subsistir os que creem em ti”.

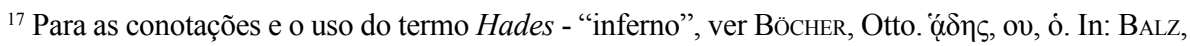
Horst \& SchneIder, Gerhard, eds. Diccionario Exegetico del Nuevo Testamento. Salamanca: Sigueme, 1996, vol. 1, cols. 91-92; BaUCKHAM, Richard. Hades, Hell. In: FreEdman, David Noel (ed). The Anchor Bible Dictionary. New York: Doubleday, 1992, vol. 3, pp. 14-15.
} 
A doxologia com a qual Paulo expressa seu estupor pela ação divina na história ( $\mathrm{Rm} 11,33-36)$, começa com uma exclamação quase barroca: "ó profundidade da riqueza e da sabedoria e do conhecimento de Deus" (v. 33), retomando o mesmo conceito expresso em Sb 17,1: "grandes e imperscrutáveis os teus juizos". A diferença, porém, é que em Romanos, ninguém é capaz de compreender as decisões de Deus, enquanto em Sabedoria trata-se de uma ignorância própria "das almas indóceis", isto é, os egípcios.

\subsection{Sexta antítese: o anjo libertador e o anjo exterminador}

A fusão expressa em Sb 18,15-16, "tua palavra onipotente [...] levava a espada afiada de teu decreto irrevogável" é retomada com formulações ligeiramente modificadas em vários versículos do Apocalipse de João: em 1,16, o vidente enxerga um Filho de homem e afirma que "de sua boca saía uma espada afiada de dois gumes"; em 2,12, Cristo apresenta-se como "aquele que tem a espada de dois gumes em sua destra" e, no v. 16 promete guerrear "com a espada afiada da minha boca" contra os hereges da comunidade; em 19,11.15, o que cavalga o cavalo branco se chama Fiel e Verdadeiro e "de sua boca saía uma espada afiada, para ferir as nações" e, de fato, em 19,21, as tropas da besta "foram mortos pela espada do que estava sentado sobre o cavalo, aquela que saía de sua boca". Neste mesmo prisma de variações deve ser considerada a afirmação de $\mathrm{Hb} 4,13$ : "a Palavra de Deus é viva, eficaz e mais penetrante do que uma espada de dois gumes".

Também em Hb 11,28, a imagem do "exterminador" que não toca os primogênitos liga-se à imagem do "exterminador" que "retrocedeu porque teve medo", de Sb 18,25.

4.6. Sétima antítese: o mar que se abre e o mar que se fecha

A afirmação paulina de que "nossos pais todos estiveram sob a nuvem e todos passaram pelo meio do mar", em 1Cor 10,1, retoma Sb 19,7-8: "a nuvem cobria de sombra o acampamento; de onde antes havia água emergiu terra seca, e do Mar Vermelho, um caminho livre", que relê Ex 14,19-22.

Merecem ainda destaque dois versículos não pertencentes ao setenário, mas cuja interpretação dos eventos do êxodo ofereceram categorias para o NT. 
O primeiro deles é o último versículo do sumário introdutório ao grande midrash (Sb 11,1-4). O v. 4 relê Ex 17,1-7 e Nm 20,2-13 e afirma: "foi dado a eles água de uma rocha áspera e remédio para a sede de uma pedra dura". Em 1Cor 10,4, Paulo faz uma aplicação cristológica: "todos beberam da mesma bebida espiritual, uma vez que bebiam da pedra espiritual que os acompanhava, e esta pedra era Cristo".

$\mathrm{O}$ outro versículo a ser considerado encontra-se nas reflexões finais ( $\mathrm{Sb}$ 19,10-22). O v. 10 abre o arremate do grande midrash qualificando o tempo do Egito como "paroikia"18, isto é, lugar de habitação provisória no estrangeiro ou, como normalmente se traduz, "exílio". Esta mesma (re)leitura faz Paulo em seu discurso na sinagoga de Antioquia da Pisídia: "o Deus deste povo Israel escolheu nossos pais e exaltou o povo na paroikía na terra do Egito" (At 13,17).

\section{À guisa de conclusão}

Como releitura da releitura, o NT utilizou Sb 10-19 de duas formas. Em primeiro lugar, o grande midrash sobre o êxodo ofereceu para os autores neotestamentários categorias e interpretações já prontas, tanto para ler os eventos do êxodo, como para ler outros acontecimentos, tanto do AT como do próprio NT.

O segundo aspecto, porém, talvez tenha maior importância: os autores neotestamentários utilizaram o próprio método midráshico ${ }^{19}$ como um dos meios para aplicar a Cristo diversas funções e atributos que no AT são prerrogativas divinas. O NT caminha a passos largos no processo de personificação que identificará ontologicamente Cristo com a Sabedoria divina, um processo que atingirá pleno amadurecimento na Patrística ${ }^{20}$, quando novas categorias serão oferecidas pela filosofia grega.

\footnotetext{
${ }^{18}$ Para o significado do termo paroikía, ver BALz, Horst. $\pi \alpha \rho o \iota \kappa i ́ \alpha, \alpha \varsigma, \dot{\eta}$. In: BALz, Horst \& SCHNEIDER, Gerhard, eds. Diccionario Exegetico del Nuevo Testamento. Salamanca: Sigueme, 1996, vol. 2, col.

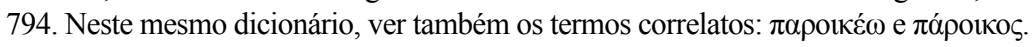

${ }^{19}$ Para os vários procedimentos deste método, ver Le DéAut, Roger. Targum du Pentateuque. Paris: Cerf, 1978, pp. 43-62; Ketterer, Eliane \& Remaud, Michel. O midraxe. São Paulo: Paulus, 2009, pp. 47-103.

${ }^{20}$ Uma exaustiva abordagem das etapas do processo de personificação da Sabedoria divina encontra-se em Gilbert, Maurice \& Aletti, Jean-Noel. A Sabedoria e Jesus Cristo. São Paulo: Paulus, 1985.
} 


\section{Referências Bibliográficas}

Babolin, Sante. Piccolo lessico di semiotica. Roma: Hortus Conclusus, 1999. Balz, Horst. $\pi \alpha \rho o \imath \kappa i ́ \alpha, \alpha \zeta, \dot{\eta}$. In: Balz, Horst; SchneIder, Gerhard (eds). Diccionario Exegetico del Nuevo Testamento. Salamanca: Sigueme, 1996, vol. 2, col. 794.

BASLez, Marie-Françoise. L'Autore della Sapienza e l'ambiente colti de Alessandria. In: Bellia, Giuseppe; Passaro, Angelo (eds). Il Libro della Sapienza: tradizione, redazione, teologia. Roma: Città Nuova, 2004, pp. 47-66.

Bauckham, Richard; Hades, Hell. In: Freedman, David Noel (ed). The Anchor Bible Dictionary. New York: Doubleday, 1992, vol. 3, pp. 14-15.

Bellia, Giuseppe; Passaro, Angelo (eds). Il Libro della Sapienza. Roma: Città Nuova, 2004 (Studia Biblica, 1).

Bellia, Giuseppe; Passaro, Angelo (eds). Il Libro della Sapienza: tradizione, redazione, teologia. Roma: Città Nuova, 2004 (Studia Biblica, 1).

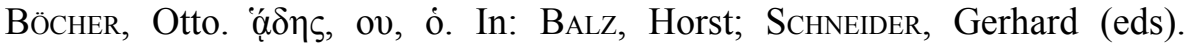
Diccionario Exegetico del Nuevo Testamento. Salamanca: Sigueme, 1996, vol. 1, cols. 91-92.

Bullinger, Ethelbert W. Figures of Speech used in the Bible: Explained and Illustrated. London - New York: Eyre; Spottiswoode - E.; J.B. Young, 1898 [também em espanhol: Diccionario de Figuras de Dicción usadas en la Biblia. Terrassa: Clie, 1985].

Conti, Martino. Sapienza. In: Girlanda, Antonio (ed). La Bibbia: Nuovissima versione dei testi originali. Cinisello Balsamo: Paoline, 1991, vol. 3, pp. 805-886.

Doré, Daniel. El libro de la Sabiduría de Salomón. Estella: Verbo Divino, 2003 (Cuadernos bíblicos, 113).

Gilbert, Maurice; Aletti. Jean-Noel. A Sabedoria e Jesus Cristo. São Paulo: Paulus, 1985 (Cadernos Bíblicos, 32).

Gilbert, Maurice. Sagesse de Salomon. In: Pirot, Louis e outros. Supplément au Dictionnaire de la Bible. Paris: Letouzey et Ané, 1986, vol. 11, cols. 58-119. 
Greimas, Algirdas Julien; Courtés, Joseph, Dicionário de semiótica. São Paulo: Cultrix, 1989.

Harl, Marguerite; Dorival, Gilles; Munnich, Olivier. A Bíblia grega dos Setenta. São Paulo: Loyola, 2007 (Bíblica Loyola, 52).

Hamilton, Mark W. Solomon. In: Sakenfield, Katharine Doob (ed). The New Interpreter's Dictionary of the Bible. Nashville: Abingdon, 2009, vol. 5, pp. 317-326.

Ketterer, Eliane; Remaud, Michel. O midraxe. São Paulo: Paulus, 2009 (Documentos do mundo da Bíblia, 9).

KolarciK, Michael. Solomon, Wisdom of. In: SAKenfield, Katharine Doob (ed). The New Interpreter's Dictionary of the Bible. Nashville: Abingdon, 2009, vol. 5, pp. 330-334.

Larcher, Claudine. Le Livre de la Sagesse ou la Sagesse de Salomon. Paris: Gabalda, 1985, Vol. 3 (Étude Bibliques. Nouvelle série, 5).

Le Déaut, Roger. Targum du Pentateuque. Paris: Cerf, 1978.

Lemche, Niels Peter. Jerusalem and King Solomon: How Writers Create the Past. In: Liverani, Mario e outros. Convegno Internazionale "Recenti tendenze nella ricostruzione della storia antica d'Israele". Roma: Academia Nazionale dei Lincei, 2005, pp. 73-86.

MunNich, Olivier. O texto da Septuaginta e seus problemas. In: Harl, Marguerite; Dorival, Gilles; Munnich, Olivier. A Bíblia grega dos Setenta. São Paulo: Loyola, 2007, pp. 119-241 (Bíblica Loyola, 52).

Patsch, Hermann. àvó $\mu v \eta \sigma i \varsigma, \varepsilon \omega \varsigma, \grave{\eta}$. In: Balz, Horst; Schneider, Gerhard, eds. Diccionario Exegetico del Nuevo Testamento. Salamanca: Sigueme, 1996, vol. 1, cols. 251-254.

Pearson, Birger A. Alexandria. In: Freedman, David Noel (ed). The Anchor Bible Dictionary. New York, Doubleday, 1992, vol. 1, pp. 152-157.

Pérez Fernández, Miguel. El midrás como método y los midrasim como obras exegéticas. Reseña Bíblica 23 (1999), pp. 53-62.

Peters, Melvin K. H. Septuagint. In: Freedman, David Noel (ed). The Anchor Bible Dictionary. New York: Doubleday, 1992, vol. 5, pp. 1093-1104. 
Porton, Gary G. Midrash. In: Freedman, David Noel (ed). The Anchor Bible Dictionary. New York: Doubleday, 1992, vol. 4, pp. 818-822.

Ravasi, Gianfranco. Sapienza (Libro della). In: Rossano, Pietro; Ravasi, Gianfranco; Girlanda, Antonio (eds). Nuovo Dizionario di Teologia Biblica. Cinisello Balsamo: Paoline, 1988, pp. 1142-1447 (I Dizionari).

Silva, Cássio Murilo Dias da; Ló, Rita de Cácia. Caminho não muito suave. Campinas: Alínea, 2011, pp. 93-104.

Silva, Cássio Murilo Dias da. Aquele que manda a chuva sobre a face da terra. São Paulo: Loyola, 2006 (Bíblica Loyola, 50).

TARADACH, Madeleine. El midrash. Introdució a la literatura midràshica, als targumim i als midrashim. Barcelona: Herder, 1989.

TAYlor, Joan E. Alexandria. In: SAKenfield, Katharine Doob (ed). The New Interpreter's Dictionary of the Bible. Nashville: Abingdon, 2009, vol. 1, p. 99.

TILly, Michael. Introdução à Septuaginta. São Paulo: Loyola, 2009.

Vílchez LínDEz, José. Sabedoria. São Paulo: Paulus, 1995 (Grande Comentário Bíblico).

Visotzky, Burton L. Midrash. In: SAKenfield, Katharine Doob (ed). The New Interpreter's Dictionary of the Bible. Nashville: Abingdon, 2009, vol. 4, pp. 81-84.

Winston, David. Solomon, Wisdom of. In: Freedman, David Noel (ed). The Anchor Bible Dictionary. New York: Doubleday, 1992, vol. 6, pp. 120-127.

Cássio Murilo Dias da Silva Doutor em Ciências Bíblicas pelo Pontifício Instituto Bíblico de Roma Professor de Antigo Testamento na Faculdade de Teologia da Pontifícia Universidade Católica do Rio Grande do Sul Porto Alegre / RS - Brasil E-mail: cassiomu@gmail.com

Recebido em: 29/10/14 Aprovado em: 11/12/14 